\title{
Effect of Oral Calcium Supplementation on Lipid Profile and Atherogenic Index of Plasma
}

\author{
Mya Thanda Sein, ${ }^{1}$ Tint Swe Latt, ${ }^{2}$ Ohnmar ${ }^{1}$ \\ ${ }^{1}$ Department of Physiology, University of Medicine 2, Yangon, Myanmar \\ 2 University of Medicine 2, Yangon, Myanmar
}

\begin{abstract}
Objective. To assess the effect of oral calcium supplementation on lipid profile and atherogenic index of plasma (AIP).

Methodology. This study was undertaken in 28 centrally obese male subjects [age 26.4 (6.5) years], BMI 31.6 (4.7) $\mathrm{kg} / \mathrm{m}^{2}$, WC $99.4(6.4) \mathrm{cm}$. All participants received six tablets of $\mathrm{CaCO}_{3}$ (250 mg of elemental calcium/ capsule, for a total of $1500 \mathrm{md} /$ day) for 8 weeks. Serum lipid profile including triglyceride, total cholesterol, HDL-C, LDL- C was measured at baseline and after intervention. AIP was calculated by using formula $=\log (T G / H D L-C)$.
\end{abstract}

Results. Oral calcium supplementation achieved a 22\% (36 mg/dL, $\mathrm{p}<0.001)$ reduction in Triglyceride from baseline [163.4 (37.9) $\mathrm{mg} / \mathrm{dL}$ ] and 19.2\% ( $5.8 \mathrm{mg} / \mathrm{dL}, \mathrm{p}<0.001$ ) increase in HDL-C from baseline [30.4 (7.4) $\mathrm{mg} / \mathrm{dL}$ )]. There were no significant treatment effects on total cholesterol [217.1 (41.21) mg/dL vs 196.3 (46.2) mg/dL] and LDL-C [155.4 (45.1) $\mathrm{mg} / \mathrm{dL}$ vs 136.3 (45.1) $\mathrm{mg} / \mathrm{dL}$. Significant reduction in serum total cholesterol and LDL-C level was only found in dyslipidemic centrally obese subjects. AIP decreased significantly by $51 \%$ with calcium carbonate treatment [median and interquartile range; $0.35(0.29-0.44)$ vs $0.17(0.04-0.44), p<0.01]$.

Conclusion. Eight-week calcium supplementation at $1500 \mathrm{mg} /$ day led to a significant change in lipid levels and AIP.

Keywords: calcium supplementation, lipid profile, atherogenic index of plasma (AIP)

\section{INTRODUCTION}

In developed and developing countries, major risks or causative factors for cardiovascular diseases are elevated blood pressure, lipid profile and obesity. ${ }^{1}$ Reduction of these risk factors has been one of the most important fields of medical research. Lifestyle changes, dietary habits and supplements to modify adiposity and hyperlipidemia have become popular as these are simple, less expensive and effective measures to reduce the cardiovascular risks.

Calcium supplementation is widely recommended to postmenopausal women for the prevention of osteoporosis. It has been established over one to two decades that dietary calcium can interact directly with lipid absorption, and can bind to bile acids and increase their excretion and lower serum cholesterol when they are consumed in doses more than the intestine can absorb. ${ }^{2,3}$ Lately, a growing body of evidence suggests that calcium supplements also have beneficial effects on insulin sensitivity, blood pressure, body weight and serum lipids. ${ }^{4-12}$ In a study by Jacqmain, low daily calcium intake is associated with greater adiposity in women and lipoprotein concentration in both sexes. ${ }^{4}$ Some studies have shown that calcium supplementation enhanced weight loss and reduced serum lipid profile in obese subjects.5,6 On the contrary, significant effect of calcium supplementation on serum lipid or body composition was not seen in healthy older men ${ }^{7}$ and normal older postmenopausal women. ${ }^{8}$ Some randomized controlled studies demonstrated that calcium supplementation has the ability to lower serum cholesterol level in hypercholesterolemic subjects ${ }^{9-11}$ and hyperlipidemic patients. ${ }^{12,13}$ However, these studies did not ascribe the beneficial effect of calcium on triglycerides. The results are still unsatisfactory with limited evidence to draw definite conclusions on the effect of calcium supplementation on lipid profile.

Dyslipidemia is commonly associated with an abnormal lipoprotein phenotype which is characterized by increased TG, decreased HDL-C and an accumulation of small dense LDL-C particles even when the levels of LDL-C are often normal. Oxidized LDL-C is taken up by immune system cells which transform to foam cells. These foam cells are trapped in the wall of the blood vessels and contribute to the formation of atherosclerotic plaques that cause arterial narrowing and lead to heart diseases. ${ }^{14}$ Serum esterase is associated with HDL-C and destroys the oxidized LDL-C. Therefore HDL-C has ability to protect against heart
e-ISSN 2308-118X

Printed in the Philippines

Copyright (C) 2014 by the JAFES

Received June 24, 2014. Accepted October 21, 2014

http://dx.doi.org/10.15605/jafes.029.02.06
Corresponding author: Mya Thanda Sein, MD Associate Professor, Department of Physiology University of Medicine 2, Yangon, Myanmar Tel. No.: 095109450

E-mail:dr.myathandasein@gmail.com 
disease. Either the ratio of LDL-c/HDL-c or TC/HDL-c is used as the best predictor of cardiovascular risk. ${ }^{15}$ The logarithmically transformed TG/HDL-C ratio is a more accurate predictor of cardiovascular risk than other previously used lipid parameters. ${ }^{16}$ Furthermore, in situations where other atherogenic risk parameters appear normal, AIP may be the diagnostic alternative. ${ }^{17}$ AIP values increased with increasing cardiovascular risk. AIP value is less than 0.1 in young children and increases up to 0.4 in men and subjects with cardiovascular risk factors such as hypertension, diabetes and dyslipidemia. It has been suggested that AIP values of less than 0.1 are associated with low risk, 0.1 to 0.24 with medium risk and above 0.24 with high $\mathrm{CV}$ risk. ${ }^{18}$ Khazaál reported that AIP is an index of highest sensitivity for predicting acute coronary events. It is a better screening tool for evaluating the cardiac risk and a monitoring index for any lipid lowering intervention. ${ }^{19}$

While abdominal obesity is more common in women than in men, the risk of cardiovascular diseases is greater in obese men than in obese women. ${ }^{20}$ This study has focused on men as cardiovascular disease is a major source of morbidity in males. Therefore, this study intended to find out the effect of oral calcium supplementation on lipid profile and atherogenic index of plasma in centrally obese male subjects.

\section{METHODOLOGY}

Apparently healthy centrally obese male subjects (WC $>90$ $\mathrm{cm}$ ), aged between 18-35 years without family history of diabetes mellitus and hypertension (blood pressure $>140 / 90 \mathrm{mmHg}$ ), history of regular exercise, chronic smoking and alcohol drinking were recruited to this study. No one was taking medications such as calcium supplements, non-steroidal anti-inflammatory, antihypertensive medications, lipid-lowering drugs, diuretics, or any other drug that affects the lipid metabolism for at least 6 months.

They were instructed to take six $\mathrm{CaCO}_{3}$ capsules daily (each capsule contains $250 \mathrm{mg}$ of elemental calcium, Medicine Supply Co. Ltd., Thailand) for 8 weeks. In the present study, dose of elemental calcium to be given and duration of study period was determined according to previous studies indicating the beneficial effect of oral elemental calcium supplementation on insulin sensitivity in 20 hypertensive patients ${ }^{21}$ and in 31 diabetic patients ${ }^{22}$ since there was an association between dyslipidemia, obesity and insulin resistance..$^{23.24}$

After a 10-hour fast, morning venous blood sample $(10 \mathrm{ml})$ and morning spot urine sample were taken before and after the 8-week supplementation period. Throughout the study period, they were allowed to take regular diet and also instructed to maintain their dietary patterns, dietary habits and usual sources of diet. Compliance was assessed by biweekly visit and review of the diet diary and physical activity diaries and tablet counts. Anthropometric data such as BMI and waist circumference, dietary assessment and physical activity assessment were done at the start, visit 2 ( $4^{\text {th }}$ week of supplementation period) and at the end of supplementation period $\left(8^{\text {th }}\right.$ week of supplementation period).

Total cholesterol (TC) and triglycerides (TG) were assayed by enzymatic colorimetric tests with cholesterol esterase cholesterol oxidase and glycerol phosphate oxidase. Highdensity lipoprotein cholesterol (HDL-C) was measured after precipitation of the apo-lipoprotein B-containing lipoproteins with phosphotungstic acid. Low-density lipoprotein cholesterol (LDL-C) was calculated from serum TC, TG and HDL-C using the Friedewald formula. ${ }^{25}$ Atherogenic index was calculated by using formula $=\log$ (TG/HDL-C). ${ }^{16}$

Serum total calcium level was measured by OCresolphthaleine-Complexone method. Serum total protein level was measured by Biuret method. Serum albumin level was measured by Bromocresol Green method. Serum ionized calcium level was calculated by using the following formula. ${ }^{26}$

$$
\begin{aligned}
& \text { Ionized calcium }(\mathrm{mg} / \mathrm{dl})=[6 \mathrm{Ca}-(\mathrm{K} / 3)] /(\mathrm{K}+6) \\
& \mathrm{Ca}=\text { Total calcium }(\mathrm{mg} / \mathrm{dl}) \\
& \mathrm{K}=(0.19 \times \mathrm{P})+\mathrm{A} \\
& \mathrm{P}=\text { Total Protein }(\mathrm{g} / \mathrm{dl}) \\
& \mathrm{A}=\text { Albumin }(\mathrm{g} / \mathrm{dl})]
\end{aligned}
$$

Serum PTH level was measured by enzyme-linked immunoassay (ELISA). Physical activities assessment was carried out by questionnaire assessment procedure. ${ }^{27}$

Urine creatinine level was measured by Jaffe-Reaction and urine calcium level was measured by O-CresolphthaleineComplexone method. Urine calcium excretion was expressed as urine calcium and urine creatinine ratio.

All continuous baseline characteristics, and laboratory parameters were expressed as mean (SD). The changes in parameters before and after calcium supplementation were analyzed by using a paired student's " $t$ " test. Skewed data were expressed as median and interquartile ranges and they were computed by non-parametric tests, MannWhitney Signed-Rank test. Differences were considered significant when $\mathrm{p}<0.05$.

\section{RESULTS}

A total of 35 subjects participated in this study. Of these, four were dropped out due to incomplete data, three subjects who did not follow the instructions were also excluded from the study. Only 28 subjects remained in this study. Table 1 shows the baseline characteristics of subjects who participated in this study. Body weight, WC and measurement of physical activity was done at the beginning, at the $4^{\text {th }}$ week and at the end of the 8 th week of 
the study period. Although there was a slight decrease in body weight and WC $(0.03 \%$ and $2 \%$ respectively) at the $8^{\text {th }}$ week of calcium supplementation, it was statistically but not clinically significant. (Table 2). Physical activity was the same during the experimental period.

Table 1. Baseline characteristics of the centrally obese male subjects, mean (SD)

\begin{tabular}{lc}
\hline \multicolumn{1}{c}{ Parameters } & Centrally obese subjects $\mathbf{( n = 2 8 )}$ \\
\hline Age $(\mathrm{yr})$ & $26.4(6.5)$ \\
Weight $(\mathrm{kg})$ & $89.6(15.6)$ \\
Height $(\mathrm{cm})$ & $168.0(5.8)$ \\
BMl $\left(\mathrm{kg} / \mathrm{m}^{2}\right)$ & $31.6(4.7)$ \\
Waist circumference $(\mathrm{cm})$ & $99.4(6.4)$ \\
Hip circumference $(\mathrm{cm})$ & $106.0(10.1)$ \\
Waist Hip Ratio & $0.98(0.01)$ \\
Resting SBP $(\mathrm{mmHg})$ & $118.6(8.0)$ \\
Resting DBP $(\mathrm{mmHg})$ & $78.8(7.9)$ \\
Resting MAP $(\mathrm{mmHg})$ & $92.1(7.6)$ \\
Heart Rate $($ beats/min $)$ & $74.8(7.2)$ \\
Physical activity $(\mathrm{kcal} / \mathrm{day})$ & $2817.8(531.9)$ \\
\hline
\end{tabular}

There was no significant change in serum total and ionized calcium before and after calcium supplementation [8.8 (1.3) vs 8.1 (1.1) and 4.2 (1.3) vs $3.9(1.6) \mathrm{mg} / \mathrm{dL}$ ]. However, urine calcium excretion $\left(\mathrm{Ca}^{2+} / \mathrm{Cr}\right.$ ratio) significantly increased $(\mathrm{p}<0.01)$ after calcium supplementation [0.06 (0.03) vs 0.09 (0.04)]. Serum PTH level decreased significantly $(\mathrm{p}<0.01)$ from 33.9 (18.6) to 23.4 (9.7) $\mathrm{pg} / \mathrm{ml}$ after calcium supplementation.

Lipid profile of the subjects is shown in Table 2. HDL-C significantly rose and TG significantly fell with calcium supplementation. There was a reduction in serum TC and LDL-C levels after calcium supplementation, but the changes were not statistically significant. Then, the subjects were subdivided into 2 groups according to the normal serum lipid level. Significant reduction in serum TC and LDL-C levels was found in dyslipidemic centrally obese subjects, but no changes were found in those with normal lipid profile.

Figure 1 showed that AIP decreased significantly by 51\% with calcium carbonate treatment [median and interquartile range; $0.35(0.29-0.44)$ vs 0.17 (0.04-0.44) $(\mathrm{p}<0.01)]$.

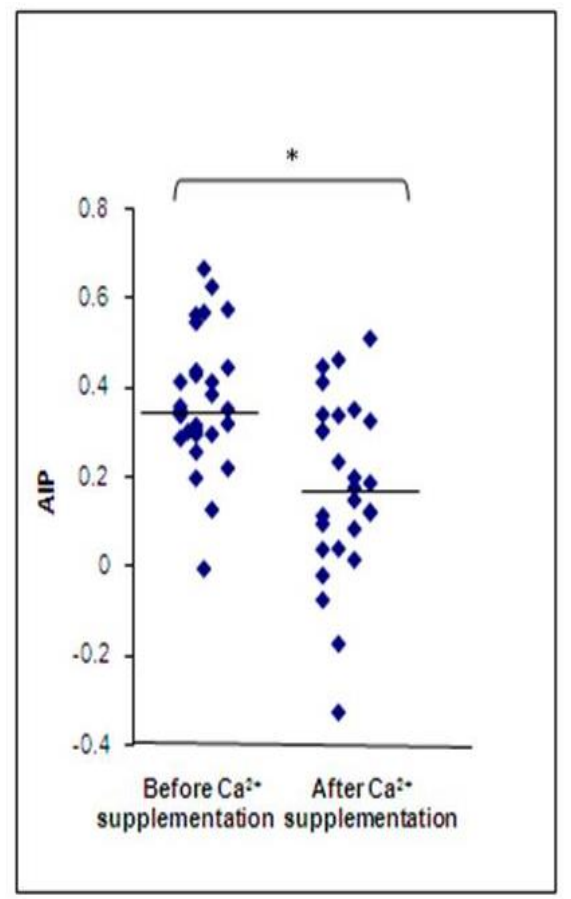

Figure 1. AIP in the centrally obese subjects before and after $\mathrm{Ca}^{2+}$ supplementation

Solid line indicates mean values.

*indicates $p<0.01$

NB: Comparison was done by using non-parametric test (Mann-Whitney Signed-rank test).

Table 2. Body weight, waist circumference and physical activity at different intervals during the

\begin{tabular}{|c|c|c|c|}
\hline $\begin{array}{c}\text { Parameters } \\
(n=28)\end{array}$ & Beginning & $4^{\text {th }}$ week & $8^{\text {th }}$ week \\
\hline Weight (kg) & $89.6(15.9)$ & $89.2(15.8)^{*}$ & $89.1(15.8)^{*}$ \\
\hline WC $(\mathrm{cm})$ & $8.28(1.06)$ & $97.9(6.0)^{*}$ & $97.4(6.0)$ * \\
\hline Physical activity (kcal/day) & $2817.8(540.4)$ & $2812.5(522.8)$ & $2807.3(531.2)$ \\
\hline
\end{tabular}

Table 3. Serum lipid profiles in centrally obese subjects before and after calcium supplementation

\begin{tabular}{|c|c|c|c|c|}
\hline Parameters & & Before & After & Changes \\
\hline $\mathrm{TC}(\mathrm{mg} / \mathrm{dL})(\mathrm{n}=28)$ & mean (SD) & $217.1(41.21)$ & $196.3(46.2)$ & $20.80(60.61)$ \\
\hline$<200 \mathrm{mg} / \mathrm{dL}(\mathrm{n}=12)$ & median and IQ & $178(168.9-195.1)$ & $189.7(150-215.7)$ & $3.4(-52-26.6)$ \\
\hline$>200 \mathrm{mg} / \mathrm{dL}(\mathrm{n}=16)$ & & $244.6(213,7-277.3)$ & 182(165.7-220.6) & $52.4(32.6-79.4)^{*}$ \\
\hline $\mathrm{TG}(\mathrm{mg} / \mathrm{dL})(\mathrm{n}=28)$ & mean $(\mathrm{SD})$ & $163.4(37.9)$ & $127.4(40.2)$ & $35.94(54.80)^{\star * *}$ \\
\hline$<150 \mathrm{mg} / \mathrm{dL}(\mathrm{n}=11)$ & median and IQ & 129(112.4-134.9) & $118(86-158.6)$ & $6.3(-14-48.9)$ \\
\hline$>150 \mathrm{mg} / \mathrm{dL}(\mathrm{n}=17)$ & & 191.7(166.3-200) & $128(107.3-143.2)$ & $53(34.3-84.4)^{* *}$ \\
\hline $\begin{array}{l}\mathrm{HDL}-\mathrm{C}(\mathrm{mg} / \mathrm{dL})(\mathrm{n}=28) \\
>40 \mathrm{mg} / \mathrm{dL}(\mathrm{n}=2)\end{array}$ & mean $(S D)$ & $30.4(7.4)$ & $36.3(8.9)$ & $-5.84(12.15)^{\star * *}$ \\
\hline$<40 \mathrm{mg} / \mathrm{dL}(\mathrm{n}=26)$ & median and IQ & $29.1(25.3-31.5)$ & $37.6(29-42.4)$ & $-6.1(-15.4-1.1)^{\star *}$ \\
\hline LDL-C (mg/dL)(n=28) & mean (SD) & $155.35(45.11)$ & $136.34(44.97)$ & $19(60.1)$ \\
\hline$<130 \mathrm{mg} / \mathrm{dL}(\mathrm{n}=11)$ & median and IQ & 110.8(106.8-121) & 137.9(85.76-166.7) & $-27.6(-58.8-24.2)$ \\
\hline$>130 \mathrm{mg} / \mathrm{dL}(\mathrm{n}=17)$ & & 186(155.9-208.9) & $125.8(104.3-158.8)$ & $55.4(18.5-72.1)^{\star \star}$ \\
\hline
\end{tabular}




\section{DISCUSSION}

The US Institute of Medicine Food and Nutrition Board currently designates a tolerable calcium carbonate upper intake level of $2500 \mathrm{mg} / \mathrm{d}$ for adults 19-50 years of age as being free of adverse health effects for nearly all persons in the general population..$^{28}$ In this study, the subjects were allowed to take regular diet with supplementation with $\mathrm{CaCO}_{3} 1500 \mathrm{mg} /$ day, this dose would not pose any health risk.

After calcium supplementation, overall reduction of serum triglyceride level was $22 \% \quad(n=28)$. Those with high triglyceride level $(>150 \mathrm{mg} / \mathrm{dL} ; \mathrm{n}=17)$ exhibited more dramatic change, with a median decrease of $53 \mathrm{mg} / \mathrm{dL}$ $(27.6 \%)$ whereas there was no significant treatment effect in those with normal triglyceride level $(n=11)$. Yacowitz et al., reported that there was a mean decrease of $56.3 \mathrm{mg} / \mathrm{dL}$ in serum triglyceride level in 11 hypertriglyceridaemic male subjects with calcium carbonate supplementation $(0.89 \mathrm{~g})$ for 21 days. ${ }^{11}$ Reid et al., reported no significant effect on triglyceride in 108 healthy older men with 1200 mg elemental calcium supplementation for 2 years. ${ }^{7}$ In their study, participants consumed a regular-fat diet (about $28 \%$ of total calorie intake) and baseline level of triglyceride was $129.21 \mathrm{mg} / \mathrm{dL}$ (69.03). Although the duration of their study was much longer than ours, their result is quite different. The reason may probably be the baseline triglyceride level of the subjects, their study included both normo- and hypertriglyceridaemia.

Contrary to the present study which used $1500 \mathrm{mg} /$ day of calcium carbonate for 8 weeks, Shidfar et al., reported that there was no significant treatment effect on the serum triglycerides in 49 overweight hypertriglyceridaemic male subjects [baseline value $238.7(81.2) \mathrm{mg} / \mathrm{dL}$ ] who were treated with $1250 \mathrm{mg} /$ day of calcium for 8 weeks. ${ }^{13}$

Denke et al.,(1993) also reported a non-significant change in TG in 13 healthy men with moderate hypercholesterolemia by high dose (2200 mg per day) of calcium supplementation for 10 day period. ${ }^{10}$ It could be assumed that the serum lipid level before the trial and the dose and duration of calcium supplementation might be probable reasons for the beneficial effect of calcium on lipid profile.

In the present study, 16 subjects with the highest TC level $(>200 \mathrm{mg} / \mathrm{dL})$ showed a $21.4 \%$ decrease in serum cholesterol level with a median decrease of $52.4 \mathrm{mg} / \mathrm{dL}$. Ten of the 16 hypercholesterolaemic subjects had normal cholesterol level $(<200 \mathrm{mg} / \mathrm{dL})$ after 8-weeks calcium supplementation. Denke et al., ${ }^{10}$ Yocowitz et al., ${ }^{11}$ and Shidfar et al., ${ }^{13}$ also reported reduction in TC with calcium supplementation. However, amount reduction (52.4 $\mathrm{mg} / \mathrm{dL}$ ) was a bit higher in the present study when compared with these previous studies; i.e., $6 \%, 23.6 \mathrm{mg} / \mathrm{dL}$ and $28.3 \mathrm{mg} / \mathrm{dL}$ respectively. Reid et al., reported that there was no significant change in serum total cholesterol level after intervention because participants had lower cholesterol before the trial. 7,8

The significant treatment effect of calcium supplementation on HDL-C and LDL-C was also seen in the present study. However, this treatment effect on LDL$\mathrm{C}$ was only seen in subjects with abnormal lipid level but not seen in the subjects with normal lipid concentration. A $29.8 \%$ decrease in LDL-C with median decrease of 55.4 $\mathrm{mg} / \mathrm{dL}$ was seen in 17 subjects with high LDL-C level $(>130 \mathrm{mg} / \mathrm{dL})$. Among them, only 7 subjects fell within normal range $(60$ to $130 \mathrm{mg} / \mathrm{dL})$ after calcium supplementation. HDL-C increased significantly from 30.4 (7.4) $\mathrm{mg} / \mathrm{dL}$ to 36.3 (8.9) $\mathrm{mg} / \mathrm{dL}(\mathrm{p}<0.001)$ with $19.2 \%(5.84$ $\mathrm{mg} / \mathrm{dL}, \mathrm{p}<0.001)$ increase from baseline. Abnormal low HDL-C level (baseline value $<40 \mathrm{mg} / \mathrm{dL}$ ) was observed in 26 of the 28 subjects and there are just 10 subjects who reached the normal HDL-C level by oral calcium supplementation.

In the present study, median and interquartile range of AIP was 0.35 (0.29-0.44), predicting a higher risk for cardiovascular disease. The study done by Ceska et al., reported that AIP values of less than 0.1 are associated with low risk, 0.1 to 0.24 with medium risk and above 0.24 with high CV risk. ${ }^{18}$ The present study also found that AIP decreased significantly by $51 \%$ with calcium carbonate treatment. Previous animal studies also reported a protective effect of supplemental calcium against the atherogenic process in young goats. ${ }^{29}$ Moreover, supplementation of calcium together with an atherogenic diet has been shown to inhibit atherosclerosis in rabbits. ${ }^{30}$

Atherogenic index of plasma (AIP) is the new marker of atherogenicity, because it is directly related to the atherosclerosis risk. Hypertriglyceridemia increases the activity of hepatic lipase (HL) which results in the increase of HDL-C catabolism (degradation of HDL-C). Each degradation of $1 \mathrm{mg}$ HDL-C will correlate with a $2 \%$ increase in the risk of coronary heart disease (CHD). ${ }^{31,16}$ Some epidemiological studies found a significant inverse correlation between water hardness and mortality from CVD for both males and females. ${ }^{32}$ Mortality rate of acute myocardial infarction was 34\% lower in the areas supplied with water containing more calcium $(>70 \mathrm{mg} / \mathrm{L})$ as compared to those living in an area where the drinking water calcium level was $<31 \mathrm{mg} / \mathrm{L}$.

In this study, dietary and physical activity records were taken every fortnight to ensure that all subjects kept their calorie intake as well as physical activity relatively constant for the whole study period. They exhibited only a slight change in body weight (mean difference in BW: 0.5 $\mathrm{kg}$ and percent change: $0.03 \%$ of the initial weight) and fat loss (mean difference in WC: $2 \mathrm{~cm}$ and percent change: $2 \%$ of the initial WC). Fat loss (2\%) was not clinically significant, even though it was statistically significant. 
Both serum total calcium and serum free ionized $\mathrm{Ca}^{2+}$ were not modified after calcium supplementation. However, oral calcium supplementation increased urine calcium excretion, expressed as $\mathrm{Ca}^{2+} / \mathrm{Cr}$ ratio, indicating that calcium intake is high because $10 \%$ of ingested calcium is normally excreted in the urine. In this study, it was also noted that serum PTH level significantly decreased after calcium supplementation. This finding was consistent with the studies of Kynast-Gales and Massey (1992),33 Levey et al., ${ }^{34}$ and Sanchez et al. ${ }^{21}$ They showed that an increase in dietary calcium reduces the serum PTH concentration. The observed decrease in serum PTH, increased urine calcium excretion and normal serum calcium level after intervention also support that $\mathrm{Ca}^{2+}$ homeostasis seems to be maintained at the expense of serum PTH level in centrally obese subjects before calcium supplementation. Centrally obese individuals who participated in this study might not be meeting the average requirement for calcium in their diet.

Calcium has the ability to modulate energy metabolism through calcitropic hormone concentrations: 1-25 DHCC and PTH. ${ }^{35-38}$ Vitamin D and PTH increase calcium uptake by the adipocytes promoting lipogenesis. With oral calcium supplementation, PTH and vitamin D levels are decreased and have opposite effects on the adipocytes. ${ }^{35} \mathrm{It}$ could explain the reduction in body fat with calcium supplementation due to lipolysis and it can be expected to increase serum lipid profile. In contrast, the present study showed evidence of the serum lipid reduction for individual parameters.

Although fecal calcium excretion was not assessed in this study, observed decrease in serum lipid level after calcium supplementation might probably be attributable to mechanisms related to fat absorption in the gastrointestinal tract. Denke et al. ${ }^{10}$ have demonstrated that calcium binds to fatty acids in the intestines and forms insoluble calcium-fatty acid soaps, thereby reducing saturated fatty acid absorption and increasing fecal excretion. Saunders et al. (1988) also found that there was not only an increase in fecal fatty acid excretion but also an increase in fecal bile acid excretion after $2.4 \mathrm{~g}$ of calcium supplementation. ${ }^{39}$ These reductions in saturated fatty acid absorption and bile acid reabsorption could lower serum cholesterol concentrations.

One limitation of the present study is that a control group on placebo was not included in this study design since a randomized, double-blind, placebo controlled design provides the strength of the study and documents the success of the intervention. Yet, the present study provides preliminary support for an important contributory role of elemental calcium in improving dyslipidemia and thus reducing risk of cardiovascular disease in centrally obese male subjects. Further confirmatory studies using randomized control trial with longer intervention period are recommended.

\section{CONCLUSION}

In conclusion, it seems that $1500 \mathrm{mg} /$ day of calcium supplementation led to significant changes in serum lipid level, thereby decreasing AIP. The present study established the contributory role of elemental calcium in decreasing risk factors of cardiovascular diseases in individuals with higher adiposity.

\section{References}

1. Wu HY, Chen LL, Zheng J, Liao YF, Zhou M. Simple anthropometric indices in relation to cardiovascular risk factors in Chinese type 2 diabetic patients. Chin J Physiol. 2007;50(3):135-42.

2. Govers MJ, Van der Meet R. Effects of dietary calcium and phosphate on the intestinal interactions between calcium, phosphate, fatty acids, and bile acids. Gut. 1993;34:365-70. http://dx.doi.org/10.1136/gut.34.3.365.

3. Mitchell WD, Fyfe T, Smith DA. The effect of oral calcium on cholesterol metabolism. J Atheroscler Res. 1968;8:913-22. http://dx.doi.org/10.1016/S0368-1319(68)80005-5.

4. Jacqmain M, Doucet E, Després J, Bouchard C, Tremblay A. Calcium intake, body composition, and lipoprotein-lipid concentrations in adults. Am J Clin Nutr. 2003;77:1448-52.

5. Major GC, Alarie F, Doré J, Phouttama S, Trembl A. Supplementation with calcium and vitamin D enhances the beneficial effect of weight loss on plasma lipid and lipoprotein concentrations. Am J Clin Nutr.2007;85:54 -59.

6. Torres MR, Francischetti EA, Genelhu V, Sanjuliani AF. Effect of a high-calcium energy-reduced diet on abdominal obesity and cardiometabolic risk factors in obese Brazilian subjects. Int J Clin Pract. 2010; 64(8):1076-83.

http://dx.doi.org/10.1111/j.1742-1241.2009.02312.x.

7. Reid IR, Ames R, Mason B, et al. Effects of calcium supplementation on lipids, blood pressure, and body composition in healthy older men: a randomized controlled trial. Am J Clin Nutr. 2010;91: 131-9. http://dx.doi.org/10.3945/ajen.2009.28097.

8. Reid IR, Mason B, Horne A, et al. Effects of calcium supplementation on serum lipid concentrations in normal older women: a randomized controlled trial. Am J Med. 2002; 112:343-7. http://dx.doi.org/10.1016/S0002-9343(01)01138-X.

9. Bell L, Halstenson CE, Halstenson CJ, Macres M, Keane WF. Cholesterol-lowering effects of calcium carbonate in patients with mild to moderate hypercholesterolemia. Arch Intern Med. 1992;152:2441-4 http://dx.doi.org/10.1001/archinte.1992.00400240061010.

10. Denke MA, Fox MM, Schulte MC. Short-term dietary calcium fortification increases fecal saturated fat content and reduces serum lipids in men. J Nutr. 1993;123:1047-53.

11. Yacowitz H, Fleischman AI, Bierenbaum ML. Effects of oral calcium on serum lipids in man. BMJ. 1965;1:1352-4. http://dx.doi.org/10.1136/bmj.1.5446.1352.

12. Carlson LA, Olsson AG, Oro L, Rossner S. Effects of oral calcium on serum cholesterol and triglycerides in patients with hyperlipidemia. Atherosclerosis 1971;14:391-400. http://dx.doi.org/10.1016/00219150(71)90067-0.

13. Shidfar F, Moghayedi M, Kerman SRJ, Hosseini S, Shidfar S. Effects of a calcium supplement on serum lipoproteins, apolipoprotein B, and blood pressure in overweight men. Int $\mathrm{J}$ Endocriol Metab. 2010;8(4):194-200.

14. Berg JM, Tymoczko JL, Stryer L. Biochemistry. 5th ed. WH, Freeman and company: New York, 2007.

15. Grover SA, Levington C, Panquest S. Identifying adults at low risk for significant hyperlipidemia: a validated clinical index. J.Clin.Epidemol.1999;52:49-55. http://dx.doi.org/10.1016/S08954356(98)00139-5.

16. Dobiasova M. Atherogenic index of plasma [log(triglyceride/HDL-CCholesterol)]:Theoretical and practical implications. Clin Chem. 2004; 1113-5.

17. Nwagha UI. Atherogenic index of plasma as useful predictor of cardiovascular risk among postmenopausal women in Enugu, Nigeria. Afr Health Sci. 2010; 10(3): 248-52.

18. Ceska R. Clinical implications of the metabolic syndrome. Diabetes Vasc. Dis Res. 2007;4(3):S2-S4. 
19. Khazaál MS, (2013). Atherogenic Index of Plasma (AIP) as a parameter in predicting cardiovascular risk in males compared to the conventional dyslipidemic indices (cholesterol ratios). Karbala J. Med. 2013; 6(1): 1506-11.

20. Go AS, Mozaffarian D, Roger VL, et al. Heart disease and stroke statistics--2013 update: a report from the American Heart Association. Circulation. 2013;127(1):2-4.

21. Sanchez M, de la Sierra A, Coca A, et al. (1997) Oral calcium supplementation reduces intraplatelet free calcium concentration and insulin resistance in essential hypertensive patients. Hypertension. 1997; 29: 531-6. http://dx.doi.org/10.1161/01.HYP.29.1.531

22. Pikilidou MI, Lasaridis AN, Sarafidis PA, et al. Insulin sensitivity increase after calcium supplementation and change in intraplatelet calcium and sodium-hydrogen exchange in hypertensive patients with Type 2 diabetees. Diabetic Medicine. 2009; 26: 211-9. http://dx.doi.org/10.1111/j.1464-5491.2009.02673.x.

23. Albrink MJ, Meigs JW. The relationship between serum triglycerides and skinfold thickness in obese subject. Ann NY Acad Sci. 1967;131:673-7.

24. Davidson P, Albrink MJ. Abnormal plasma insulin response with high plasma triglycerides independent of clinical diabetes or obesity. J Clin Invest. 1966;45:1000

25. Friedewald WT, Levy RI, Fredrickson DS. Estimation of the concentration of low-density lipoprotein cholesterol in plasma, without use of the preparative ultracentrifuge. Clin Chem. 1972; 18 499-502.

26. Pottgen P, Davis ER: Why measure total calcium? Clin Chem. 1979;22: $1752-1753$.

27. Sallis JF, Haskell WL, Wood PD, et al. Physical activity assessment methodology in the five-city project. Am J Epidemiol. 1985; 121 (1): 91-106.

28. Institute of Medicine. Dietary reference intakes for calcium and vitamin D. Washington, DC: Institute of Medicine. 2010.

29. Hia'es TG, Jacobson NL, Beitz D C , Littledike ET. Dietary calcium and Vitamin D: risk factors in the development of atherosclerosis in young goats. J Nutr. 1985; 115: 167-78.
30. Hsu HH, Culley NC. Effects of dietary calcium on atherosclerosis, aortic calcification, and icterus in rabbits fed a supplemental cholesterol diet. Lipids Health Dis. 2006; 5:16. http://dx.doi.org/10.1186/1476-511X-5-16.

31. Susanti E, Donosepoetro M, Patellong I, Arif M. Differences between several atherogenic parameters in patients with controlled and uncontrolled type 2 Diabetes Mellitus. Med J Indones. 2010; 19(2): 103-8. http://dx.doi.org/10.13181/mji.v19i2.392.

32. Monarca S, Zerbini I, Donato F. Drinking-water hardness and cardiovascular diseases: A review of epidemiological studies 19792004. World Health Organization August 2004

33. Kynast-Gales S A, Massey L K. Effect of dietary calcium from dietary products on ambulatory blood pressure in hypertensive men. J American Diet Assoc. 1992; 92: 1497-501.

34. Levey WA, Manore MM, Vaughan LA, et al. Blood pressure response of white men with hypertension to two low-sodium metabolic diets with different levels of dietary calcium. J Am Diet Assoc. 1995; 95:1280-7. http://dx.doi.org/10.1016/S0002-8223(95)00337-1.

35. Zemel MB, Shi H, Greer B, Dirienzo D, Zemel PC. Regulation of adiposity by dietary calcium. FASEB J. 2000;14:1132-8.

36. Zemel MB. Nutritional and endocrine modulation of intracellular calcium: implications in obesity, insulin resistance and hypertension. Mol Cell Biochem. 1998;188:129-36. http://dx.doi.org/10.1023/A:1006880708475.

37. Shi H, Halvorsen YD, Ellis PN, Wilkison WO, Zemel MB. Role of intracellular calcium in human adipocyte differentiation. Physiol Genomics. 2000;3:75-82.

38. Michaud EJ, Mynatt RL, Miltenberger RJ, et al. Role of the agouti gene in obesity. J Endocrinol. 1997;155:207-9. http://dx.doi.org/10.1677/joe.0.1550207.

39. Saunders D, Sillery J, Chapman R. Effect of calcium carbonate and aluminum hydroxide on human intestinal function. Dig Dis Sci. 1988 33: 408-13. http://dx.doi.org/10.1007/BF01536023

Articles and any other material published in the JAFES represent the work of the author(s) and should not be construed to reflect the opinions of the Editors or the Publisher. Authors are required to accomplish, sign and submit scanned copies of the JAFES Declaration: that the article represents original material, that is not being considered for publication or has not been published or accepted for publication elsewhere. Consent forms, as appropriate, have been secured for the publication of information about patients; otherwise, authors declared that all means have been exhausted for securing such consent. The authors have signed disclosures that there are no financial or other relationships that might lead to a conflict of interest. All authors are required to submit Authorship Certifications that the manuscript has been read and approved by all authors, and that the requirements for authorship have been met by each author.

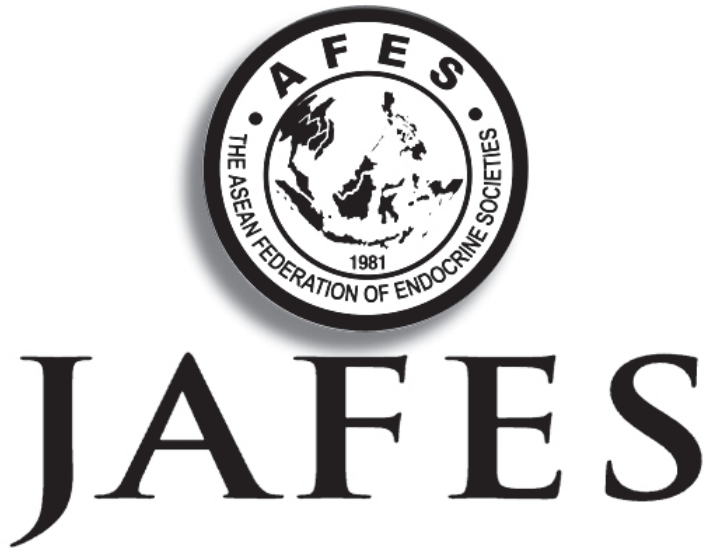

\section{A new venue for publishing your original articles. Visit www.ASEAN-endocrinejournal.org for Instructions to Authors.}

